\title{
STRUKTUR MASYARAKAT DAN KEPEMIMPINAN: KASUS PEDESAAN DI JAWA
}

\author{
Elsje Pauline Manginsela
}

\begin{abstract}
This paper aims to examine the influence of the meeting of two cultures, namely the Eastern culture (Javanese) and the West (Europe mainly Dutch), which each has a different social structure. The Ducth culture has affected rural communities in Java. This study is based on secondary data collected from literature. The problem addressed in this paper is, whether socio-political system of a traditional nature is still alive and gives benefits to rural socio-economic development. Based on the framework of Etzioni and Tjondronegoro applied to the structure of community and leadership in Java, it can be concluded that: (1) Nepotism is losing its grips in some places/villages in Java. However, in some villages, it is still preserved. (2) There is a marginalization occuring to the most vulnerable groups. (3) Sodality can still be found at the village level. (4) Congruent type in rural communities in Java, which is still alive in certain villages, is a type of Nepotism-Loyalty. In short, the traditional socio-political system still applies in Java and it has a tendency to marginalize the landless communities. For development purposes every party has to consider this vulnerable groups so that such groups can also benefit. If this happen the development will be justly distributed.
\end{abstract}

Keywords: nepotism, poliadic and sodality, rural, java

\section{ABSTRAK}

Tulisan ini bertujuan mengkaji pengaruh pertemuan dua kebudayaan, yaitu kebudayaan Timur (masyarakat Jawa) dan Barat (Eropah terutama bangsa Belanda), yang masing-masing mempunyai struktur sosial yang berbeda terhadap masyarakat pedesaan Jawa. Penelitian ini berdasarkan kajian data sekunder yang dikumpulkan dari studi literatur. Permasalahannya yang disoroti dalam tulisan ini adalah, apakah sistem sosial-politik yang bersifat tradisional ini masih hidup dan menguntungkan masyarakat pedesaan dalam pembangunan sosial-ekonomi pada masa sekarang? Berdasarkan kerangka pemikiran Tjondronegoro dan Etzioni yang diterapkan pada struktur masyarakat dan kepemimpinan di Jawa maka dapat disimpulkan bahwa: (1) Nepotisme mengendor terjadi di beberapa tempat/desa di Jawa tetapi di desa lain masih dipertahankan. (2) Terdapat gejala bahwa kelompok masyarakat yang paling lemah di pedesaan termarjinalisasi dari kelompok kerja sama pada masyarakat desa. (3) Daya hidup sodaliti masih dapat ditemukan ditingkat desa. (4) Tipe kongkruen untuk pedesaan Jawa adalah tipe Nepotisme-Setia, yang masih hidup di desa-desa tertentu. Dengan demikian sistem sosial-politik tradisional masih hidup di Jawa yang terdapat kecenderungan memarjinalkan kelompok masyarakat yang tak bertanah. Untuk itu pembangunan masyarakat perlu mempertimbangkan masyarakat yang lemah agar manfaat pembangunan dapat dinikmati secara merata.

Kata kunci: nepotisme, poliadik and sodaliti, Pedesaan Jawa 


\section{PENDAHULUAN}

Kedatangan bangsa Eropa di Jawa menyebabkan bertemunya dua kebudayaan yang berbeda, yaitu kebudayaan Timur dan Barat yang mempunyai struktur sosial yang berbeda. Akibat pertemuan dua bangsa itu kebudayaan Jawa terkena pengaruh kebudayaan Barat yang sangat besar (Burger, 1983:1; Isma'il 1997:36),). Disini orangorang Eropa khususnya orang-orang Belanda mengembangkan beberapa pikiran penting: sebagai penakluk, mereka merasa memiliki hak feodal atas tanah, dengan demikian atas pajak, serta hak pemecahan masalah-masalah pengendalian politik dan ekonomi terbaik dan termurah. Mereka menggunakan perantara-perantara ahli - yaitu, pemimpin-pemimpin tingkat tinggi pribumi dan petani-petani Cina yang membayar pajak kepada Belanda (Sutherland, 1984:10).

Dalam konteks keyakinan ini, Jawa dilihat sebagai masyarakat yang feodal yang korup, dan kebudayaannya yang telah mencapai tingkatan tinggi. Untuk itu, kerajaan-kerajaan Jawa yang semi-birokratis dan rumit memerlukan tambahan semangat dari dinamisme Eropa agar tanah menjadi produktif. Negara Timur yang statis ini dapat diusahakan supaya menghasilkan barangbarang dan jasa-jasa yang diperlukan oleh Negeri Belanda, namun tanpa membahayakan kepasifan yang hakiki dan berguna itu. Oleh karena itu pembaruan tanggapan politik yang kreatif terhadap perubahan sosial dan ekonomi tidak dapat dibiarkan oleh dogma kolonial. Akibat dari kemandegan yang dipaksakan ini selanjutnya akan membentuk citra baru bagi Jawa, yang luar biasa, dimana elite priyayi secara alamiah terlihat sebagai lebih cenderung mementingkan ilmu klenik dan pelaksanaan upacara-upacara daripada menjalankan kekuasaan yang sebenarnya. Setelah perang Dunia Kedua ketika kekangan kolonial ditiadakan, irrasionalitas kebudayaan Jawa berkembang lagi di bidang politik, dimana gagasan-gagasan lama tentang kekuasaan dari perilaku yang serasi kemudian dikenali sebagai kebangkitan kembali patrimonialisme dan neotradisionalisme (Sutherland, 1984:11).

Dalam kepemimpinan, diharapkan penerapan sistem demokrasi. Demokrasi disini dimaksud- kan seperti yang dikemukakan oleh Hatta (Tjiptoherijanto dan Prijono, 1983:17) bahwa struktur demokrasi yang hidup dalam diri bangsa Indonesia harus berdasarkan pada demokrasi asli yang berlaku di desa. Ide dasar demokrasi, berupa pengikutsertaan rakyat dan persetujuan umum dalam pencapaian keputusan dengan memelihara persetujuan bersama. Kelihatannya ini mencerminkan suatu hubungan sosial dasar yang ditemui di desa-desa Indonesia, yang pernah memberikan jaminan perlindungan dan keperluan pokok kepada masyarakat desa. Diduga sebelum zaman penjajahan demokrasi semacam ini telah dijalankan. Selama zaman penjajahan Belanda, perubahan-perubahan sosial-ekonomi, terutama perubahan-perubahan dalam pembagian tanah dari pemilikan individu ke pemilikan komunal, mempengaruhi hubunganhubungan antara pemilik dan penggarap serta antar strata sosial di Jawa (Tjiptoherijanto dan Prijono, 1983:17). Kenyataannya, kalau pemimpinpemimpin berhubungan baik dengan wewenang atasan desa (supra-village), semua keputusan akan ditetapkan oleh pemimpin-pemimpin formal, terutama lurah. Instruksi-instruksi dari wewenang atasan desa (supra-village) sering lebih merupakan landasan pokok dari suatu keputusan bila dibandingkan dengan keperluan dan keinginan dari masyarakat desa (Tjiptoherijanto dan Prijono, 1983). Permasalahannya sekarang, apakah sistem sosial-politik yang bersifat tradisional ini masih menguntungkan masyarakat pedesaan dalam pembangunan sosial-ekonomi pada masa sekarang?

Untuk mempertegas permasalahan maka struktur masyarakat Jawa dicoba didekati dengan membaginya menjadi: Struktur Masyarakat Jawa Lama/Tradisional dan Struktur Masyarakat Jawa Modern. Menurut Burger (Isma'il 1997:36), tingkatan dalam Struktur Masyarakat Jawa Tradisional adalah Raja-Kepala Propinsi (setingkat Bupati pada masa sekarang)-Kepala Desa-Penduduk desa atau orang kebanyakan. Tingkatan ini digunakanwalaupun untuk saat sekarang sudah telah berubah - karena diduga pengaruhnya masih ada. Dengan menduga bahwa masyarakat desa masih dipengaruhi oleh struktur masyarakat tradisional maka digunakan pemikiran Tjondronegoro (1977 \& 1984) untuk menganalisanya, karena kerangka pemikirannya membedakan antara Lembaga yang 
mencirikan struktur masyarakat tradisional dan Organisasi yang mencirikan struktur masyarakat modern. Tingkatan dalam suktur Masyarakat Jawa Modern adalah: Presiden-Gubernur-Bupati- Camat -Kepala Desa dan Penduduk Desa. Dengan berobahnya struktur masyarakat Jawa sekarang ini, ingin dilihat apakah organisasi modern yang dikemukakan oleh Etzioni (1961 dan 1975; Vedung 2011 : 28-29) dapat ditemukan dalam masyarakat di pedesaan Jawa. Untuk itu Kerangka pemikirian Etzioni digunakan sebagai alat penganalisa.

\section{KERANGKA PEMIKIRAN TEORITIS}

Kerangka pemikiran teoritis dalam artikel ini, sebagaimana dikemukakan sebelumnya menggunakan pemikiran Tjondronegoro (1977 dan 1984) untuk menganalisa masyarakat desa yang masih dipengaruhi oleh struktur masyarakat tradisional. Dan pemikiran Etzioni (1961 dan 1975) untuk melihat perobahnya struktur masyarakat di pedesaan Jawa.

\section{A. Kerangka Pemikiran Tjondronegora}

Tiga penemuan dari beberapa penemuan yang dikemukakan oleh Tjondronegoro (1977:34-35 dan 1984:246-251) dalam disertasinya, akan dipergunakan sebagai kerangka pemikiran teoritis dalam analisa, yaitu:

\section{Mengendornya Nepotisme}

Mengendornya nepotisme adalah mengendor-nya ikatan/hubungan kekeluargaan diganti dengan hubungan kenalan, tetangga dekat dan lain-lain. Praktek Nepotisme yang ditinjau dalam tulisan ini terutama pada Kepemimpinan desa tepatnya dalam pemerintahan desa.

\section{Hubungan Poliadik}

Yang dimaksudkan dengan hubungan poliadik adalah hubungan yang mencakup sejumlah pelaku sosial dengan berbagai kepentingan masing-masing yang dipertemukan dan diperjuangkan.

3. Daya hidup Sodaliti

Daya hidup sodaliti merupakan kesatuan masyarakat terkecil yang berdaya hidup, dimana kesatuan masyarakat terkecil ini tanpa ada hubungan kekeluargaan sebagai ciri khas tetapi hubungan kepentingan yang ada dan tanpa menghapus hubungan primer.

\section{B. Kerangka Pemikiran Etzioni}

Etzioni (1961:12; Lohmann and Lohmann 2002) mengemukakan pemikirannya dengan meninjau jenis kekuasaan yang diterapkan dan keterlibatan peserta dalam suatu masyarakat dalam bentuk tipologi seperti pada Tabel 1. Pada Tabel 1 terdapat tipe-tipe yang kongkruen, yaitu tipe 1, 5 dan 9 dengan penerapan dan keterlibatan peserta yang berbeda, yaitu:

\section{Tipe 1. Paksaan-Menarik Diri}

Dimana jenis kekuasaan yang diterapkan adalah kekuasaan paksaan dan dengan keterlibatan peserta yang menarik diri.Misalnya, pada penerapan tanam paksa pada zaman penjajahan Belanda, kekuasaan paksaan yang diterapkan menyebabkan petani sebagai peserta dalam keterlibatannya menarik diri.

\section{Tipe 5. Imbalan - Pamrih}

Pada tipe ini jenis kekuasaan yang diterapkan adalah dengan imbalan dan keterlibatan peserta adalah karena pamrih.Hal ini dapat kita jumpai dalam perusahaan-perusahaan dimana kekuasaan yang dijalankan adalah kekuasaan Imbalan dengan keterlibatan pamrih.Disini peserta tidak mau bekerja apabila tidak dibayar/diberi upah.

Tipe 9. Normatif-Moral

Dalam tipe ini jenis kekuasaan yang diterapkan adalah dengan Normatif dan keterlibatan peserta adalah dengan moral. Misalnya dalam kegiatan gotong royong dimana kekuasaan normatif dan keterlibatan yang berdasarkan moral. Contoh lain adalah pada organisasi-organisasi keagamaan.

\section{ANALISA: TEORI DAN FAKTA}

Berdasarkan pemikiran Tjondronegoro (1977 dan 1984) Etzioni (1961 dan 1975) untuk menganalisa struktur masyarakat dan kepemimpinan di pedesaan Jawa, sebagai berikut: 
Tabel 1. Tipologi dari hubungan ketaatan

\begin{tabular}{c|ccc}
\hline Jenis keterlibatan & Menarik diri & Pamrih & Moral \\
\hline Jenis kekuasaan & & & \\
Paksaan & Paksaan-Menarik diri & Paksaan- Pamrih & Paksaan- Moral \\
Imbalan & $(1)$ & $(2)$ & $(3)$ \\
Normatif & Imbalan- Menarik diri & Imbalan- Pamrih & Imbalan-Moral \\
& $(4)$ & $(5)$ & $(6)$ \\
& Normatif- Menarik diri & Normatif- Pamrih & Normatif- Moral \\
& $(7)$ & $(8)$ & $(9)$
\end{tabular}

Sumber: Etzioni 1961

\section{Mengendornya Nepotisme}

Tjondronegoro dalam penelitiannya di Desa Kendal (Jateng) dan di Desa Cibadak (Jawa Barat) pada tahun 1974 - 1975, menemukan adanya pengendoran Nepotisme di kalangan pemimpin desa.

Penemuan ini dicoba untuk diuji dengan kenyataan-kenyataan yang ada dari daerah lain di Jawa. Hasil penelian yang dilakukan oleh Universitas Satya Wacana (Tjiptoherijanto dan Prijono 1983: 38-39 ) adalah sebagai berikut: Lurah sebagai pemimpin formal dalam tugasnya secara hirarki lebih giat dalam merealisasikan programprogram yang diinstruksikan dari atas dan sebagai pemimpin informal ia harus lebih banyak mengembangkan inisiatifnya sendiri untuk memajukan desayang dipimpinnya, antara lain, dalam hal pendirian madrasah dan perbaikan mesdjid. Untuk mempermudah pelaksanaan inisiatif tersebut, seringkali lurah memanfaatkan hubungan perkerabatan diantara pamong desa.Sebagai contoh terlihat pada Desa Boyolayar, yang menunjukkan hubungan perkerabatan antara pamong desa. Dimana pada mulanya carik desa ini adalah menantu lurah karena kawin dengan anak perempuan lurah, kemudian pada suatu saat isteri carik meninggal.Hal ini mengakibatkan hubungan perkerabatan antara carik dan lurah terputus. Akan tetapi kemudian agar supaya perhubungan perkerabatan itu dihidupkan lagi atas inisiatif lurah, carik dikawinkan dengan cucu lurah. Untuk memperjelas dapat dilihat pada skema 1 .

Pada kasus di atas ini terlihat bahwa di antara para pamong desa hanya dua pamong yaitu: Modin dan Bayan (Kebayan) Dawung yang tidak mempunyai hubungan perkerabatan dengan Lurah. Selanjutnya Tjiptoherijanto dan Prijono (1983), mengemukakan bahwa dalam masyarakat yang masih bersifat tradisional, seringkali terjadi keadaan dimana pengganti lurah yang lama adalah putra lurah itu sendiri.Walaupun pemilihan lurah selalu dilakukan secara langsung dan demokrasi, tetapi bila seorang putra lurah tampil sebagai salah satu calon, kemungkinan besar ia akan terpilih.

Kasus lain seperti yang dikemukakan oleh Wigna (1979: 32,39) bahwa nepotisme sebagai suatu gejala sosial tidak hanya terjadi di Desa $\mathrm{S}$ yang merupakan salah satu desa contoh Studi Dinamika Pedesaan - Survey Agro Ekonomi (SDP - SAE) tetapi juga di desa-desa lain di Jawa Barat (Jabar) misalnya di Desa W, L, M dan C. Untuk memperjelas pada skema berikut ini, merupakan gambaran sejauh mana praktek nepotisme itu berlangsung di Desa S, menunjukkan pada kita bahwa hampir semua kuwu (kepala desa di Jabar) pada setiap generasi, baik di desa asal ST maupun AB mempunyai hubungan kekerabatan dengan kuwu-kuwu sebelumnya. Sebagai tambahan, Desa S merupakan gabungan dari Desa ST dan Desa AB.

Dengan membandingkan kenyataan dari Desa Boyolayar dan Desa S, ternyata penemuan Tjondronegoro tidak dapat dipertahankan. Bila di Kendal dan Cibadak hubungan kekerabatan digantikan dengan ikatan tinggal dekat dan lain-lain sehingga Tjondronegoro mengemukakan bahwa Nepotisme mengendor. Hal sebaliknya terjadi Desa Boyolayar dan Desa $\mathrm{S}$, nepotisme masih tetap menguat. 


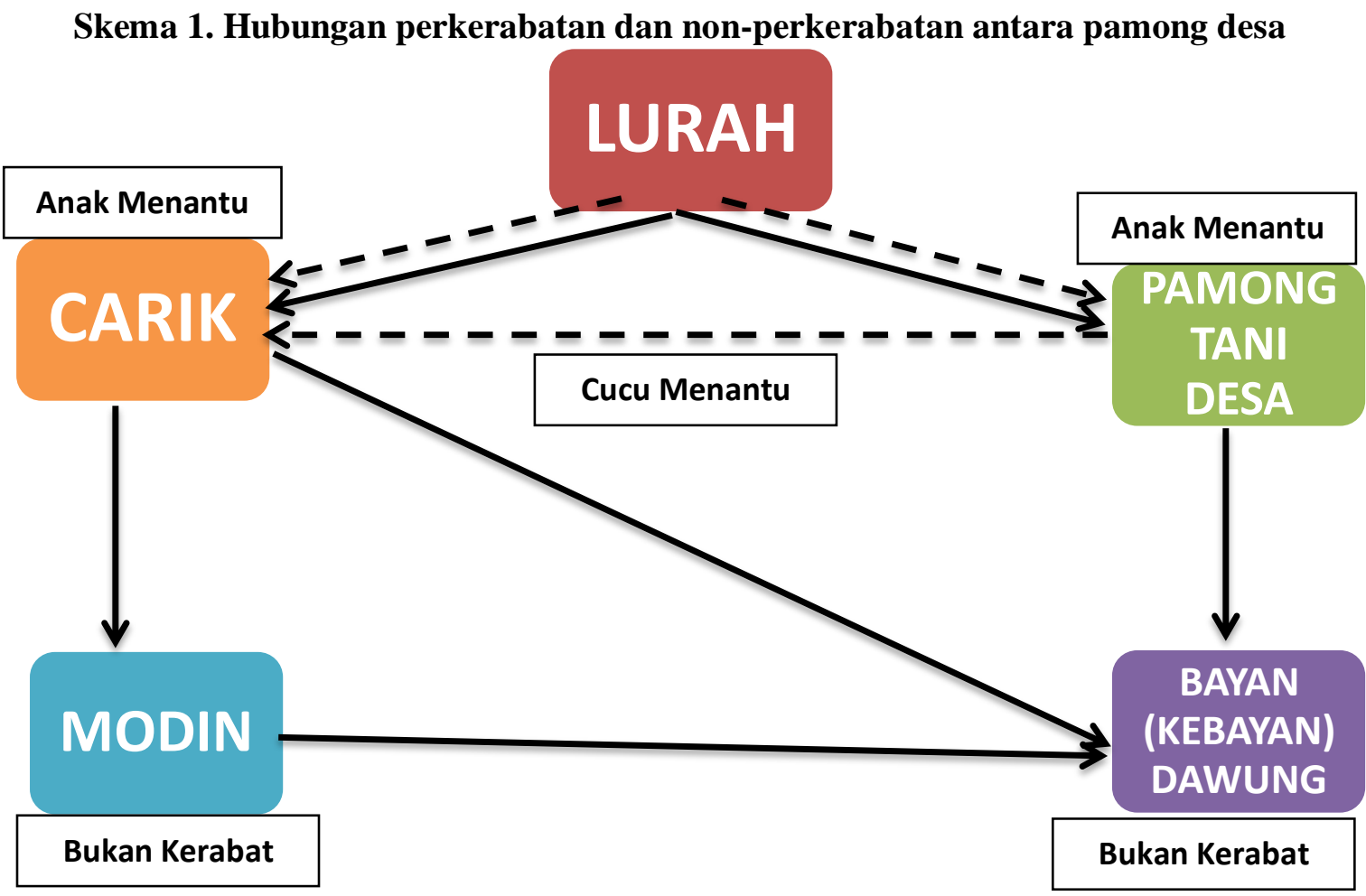

Keterangan:

---: Hubungan perkerabatan

_ _ Hubungan resmi pemerintahan

\section{Hubungan Poliadik}

Hasil penemuan Tjondronegoro di Desa Kendal dan Cibadak, yaitu adanya hubungan Poliadik, diuji dengan kenyataan yang ada di desa lain di Jawa.

Williams dan Satoto (1979) mengemukakan tentang kasus Desa Sukodono (nama samaran suatu desa di pantai utara Jawa Tengah), di mana terdapat organisasi Kesehatan (LKD). Sebagai Lembaga Kesehatan Desa yang merupakan wadah penduduk desa mengadakan hubungan poliadik ternyata mendapat rintangan di tingkat desa dari kelompok yang tidak mempunyai tanah. Untuk memperjelas penulisan Williams dan Satoto di bawah ini: Kelompok yang tidak mempunyai tanah ini, yang hampir $50 \%$ di desa, sama sekalai tidak ada peranannya dalam rencana mendirikan dan menjalankan LKD. Komposisi pengurus LKD ditentukan dalam sebuah pertemuan para pemilik tanah yang diundang oleh Lurah. Orang-orang muda yang diangkat di dalam pengurus ini dan adalah kader kader desa, juga tergolong dalam kelompok pemilik tanah besar di desa tersebut. Dan mereka tidak menganggap penting untuk melibatkan orang-orang yang tidak mempunyai tanah di dalam pengambilan keputusan tentang LKD.

Selanjutnya dikemukakan Williams dan Satoto (1979) bahwa, dengan disingkirkannya mereka yang tidak mempunyai tanah untuk mengambil bagaian yang aktif di dalam masalah-masalah LKD mungkin secara tidak langsung merupakan faktor kegagalan program sanitasi, yang sangat bermanfaat bagi mereka yang tidak mampu memperoleh kemewahan seperti sumur dan WC. Akan tetapi mereka sama sekali tidak sadar tentang program ini apalagi kemungkinan-kemungkinan dayagunanya. Kalau mereka dilibatkan dalam program sanitasi tersebut maka banylak orang yang tidak mempunyai tanah mungkin akan mendukung kader-kader kesehatan untuk melawan keputusan lurah untuk menutup program sanitasi itu. 


\section{Skema 2. Hubungan kekerabatan antar kuwu dari generasi ke generasi dari Desa $\mathbf{S}$}

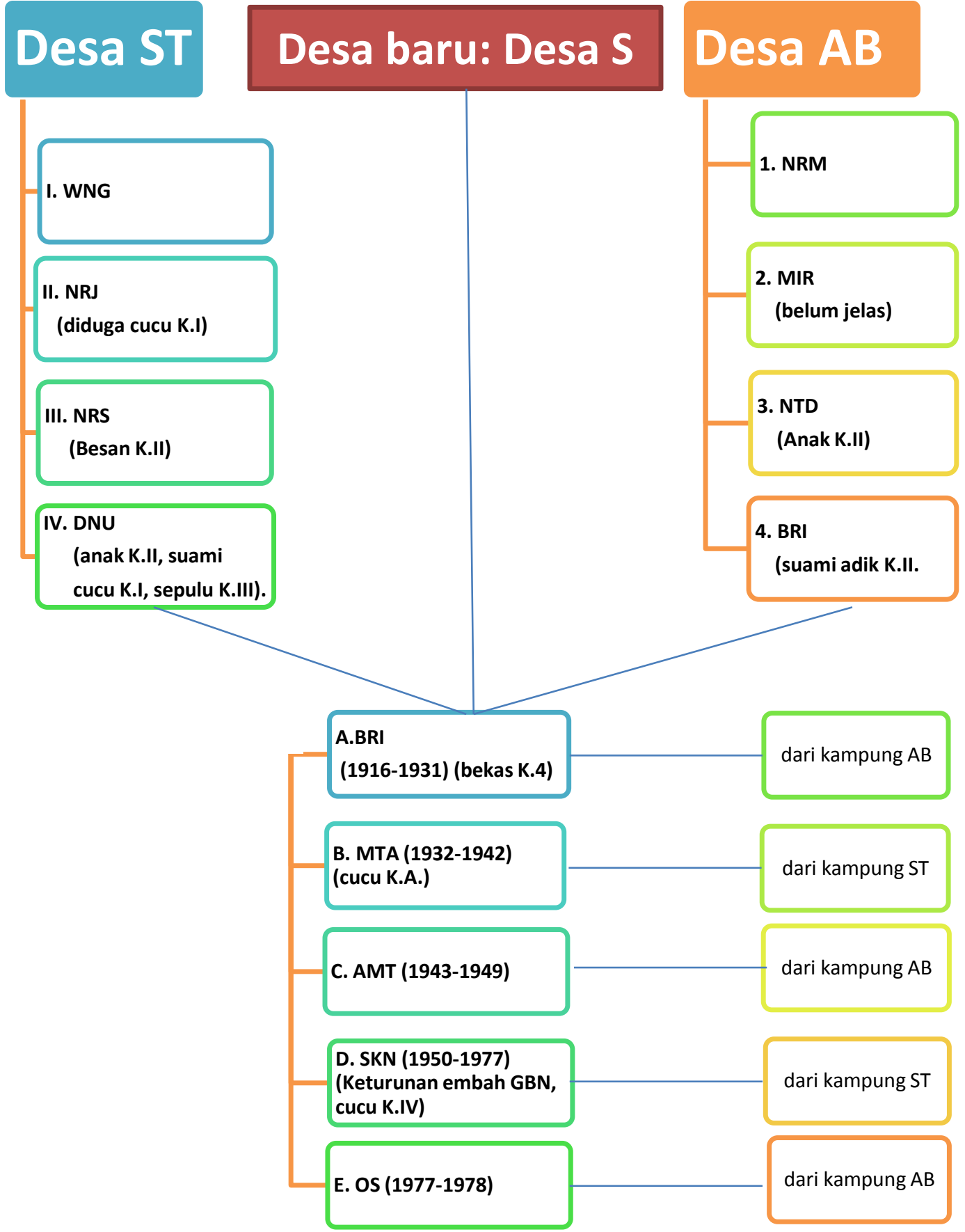

Keterangan:

- Yang dimaksud hubungan kekerabatan di sini, dilihat sebagai hubungan/ikatan, baik yang diturunkan melalui hubungan darah (biologis) maupun perkawinan.

- $\quad \mathrm{K}=$ kuwu; kpg = kampung; singkatan huruf lainnya ialah singkatan nama-nama kuwu.

Sumber: Hasil Survei Intensif SDP/SAE, 1977-1978 dalam Wigna, 1979:33 
Bukti paling dramatis dari akibat mengeluarkan orang-orang yang tidak mempunyai tanah dari proses pengambilan keputusan yang mempengaruhi kemakmurannya, kesejahteraannya adalah kasus tanah berem. Kalau sekiranya 20 keluarga pengolah tanah ini dikonsultasi lebih dahulu tentang rencana lurah untuk mengusirnya dan membagi tanah tersebut pada Wanra maka hampir pasti mereka tidak mungkin diusir ke luar, dan LKD mungkin tidak akan terlibat dalam perselisihan tanah yang sama sekali tidak perlu, yang membawa kecelakaan yang mungkin tidak mungkin diperbaiki lagi bagi citra kader kesehatan sebagai penyembuh penyakit dan promotor kesehatan.

Berdasarkan kenyataan yang di atas nampak bahwa dalam hubungan poliadik terdapat penyimpangan dimana kelompok masyarakat yang paling lemah (yang tidak memiliki tanah) disingkirkan dari kelompok kerja sama desa (LKD Sukodono). Kenyataan ini menunjukkan suatu perkembangan baru terhadap kehidupan pedesaan yang masih memerlukan penelitian lebih lanjut.

\section{Daya hidup sodaliti}

Daya hidup sodaliti ang ditemukan oleh Tjondronegoro di Desa Kendal dan Cibadak pada tahun 1977, ada pada tingkat dukuh. Untuk itu akan diuji dengan kenyataan yang ada di daerah lain di Jawa.

Wigna (1979: 32-39) mengemukakan bahwa, suasana pemerintahan di bawah kuwu OS (Kepala Desa di sebuah desa di Jabar) yang dianggap tidak mempunyai turunan langsung dari kuwu-kuwu sebelumnya, menimbulkan keresahan dikalangan masyarakat. Lebih-lebih cara pemerintahan kurwu OS bersifat otoriter dan terlalu membawa ke ABRIannya dalam suasana pemerintahan, menyebabkan rakyat baik dari kampung ST maupun kampung AB sebagai kampung asal kuwu, tidak menyenangi kuwunya. Selanjutnya dikemukakan bahwa, usaha dari pihak juru tulis lama untuk menjatuhkan kuwu OS sangat sulit,

Karena kedudukan kuwu yang cukup kuat hubungannya ke atas. Jalan yang mudah ditempuh ialah dengan membangkitkan kembali suasana perselisihan antara kampung ST dan $\mathrm{AB}$, sebagai usaha untuk memperlihatkan kepada masyarakat bahwa kuwu yang baru ini memang tidak patut dan tidak mampu memangku jabatan kuwu di Desa S. Usaha ini hampir berhasil dengan timbulnya keinginan masyarakat baik dari kampun ST maupun kampung $\mathrm{AB}$, untuk memisahkan diri kembali dari Desa S, menjadi desa masing-masing seperti semula.

Walaupun nampaknya pemekaran desa itu tidak mungkin dapat terlaksana, karena syarat-syarat seperti jumlah penduduk, pendapatan desa, lunas IPD dll belum bisa terpenuhi oleh Desa $\mathrm{S}$, namun dalam hal ini perlu diperhatikan bahwa masyarakat telah memberikan respons yang menurut mereka baik untuk kemajuan desanya, walaupun sebenarnya pemekaran desa itu bukan tujuan utama mereka.

Berdasarkan kenyataan di atas ternyata penemuan Tjondronegoro tidak dapat dipertahankan karena sodality ternyata untuk kasus Desa S masih dapat ditemukan pada tingkat desa.

Etzioni mengemukakan pemikirannya dalam bentu tipologi dari hubungan ketaatan, dimana terdapat tiga tipe kongkruen yaitu: Tipe Paksaan Menarik Diri, Tipe Imbalan-Pamrih dan Tipe Normatif-Moral. Untuk itu diuji dengan kenyataan yang ada di desa Jawa.

Wigna (1979: 32-39) mengemukakan bahwa berakhirnya pemerintahan Kuwu AMT (1949), yang memerintah Desa $S$ relatif sebentar dibandingkan dengan kuwu-kuwu lainnya, menyadarkan rakyat Desa S, bahwa mereka salah memilih kuwu. Selain tidak mempunyai teureuh kuwu, kerja sama kuwu tersebut dengan Belanda mempertebal rasa antisipasi rakyat terhadapnya. Hal ini terbukti dengan pernah ditembaknya kuwu tersebut oleh rakyat dan berakhir dengan tuntutan rakyat supaya segera meletakkan jabatan.

Selanjutnya dikemukakan bahwa, kesadaran tersebut diikuti pula dengan menampilkan calon tunggal SKN mengantikan kuwu lama, yang dianggap patut menjabat kedudukan tersebut. Dia adalah keturunan langsung dari salah satu pendiridesa asaldan mempunyai teureuh kuwu. Disamping itu juga masyarakat pernah mengenalnya sebagai pembela rakyat disaat gerilya. Untuk menjaga jangan sampai harapan masyarakat gagal, beberapa orang penduduk memaksa kesanggupan calon kuwu tersebut dengan cara menangkapnya di kebun di saat ia sedang 
menyadap nira, sewaktu cuti dari pekerjaan di Bandung. Kemudian diminta kesanggupannya untuk menjadi kuwu di desanya. Setelah melalui penjagaan ketat agar tidak dapat kembali ke Bandung, akhirnya diterimalah tawaran tersebut, dan terpilih ia sebagai kuwu Desa $\mathrm{S}$ yang mendapat dukungan besar baikdari kampung ST maupun kampung AB. Sebagai kuwu harapan rakyat, dia berhasil membuktikan kemampuannya sebagai kuwu yang dapat berbicara ke atas demi kepentingan rakyatnya dan diterimasebagai seorang pemimpin yang berhasil. Kemampuannya dibuktikan dengan berhasilnya meredakan dan menyatukan perselisihan yang telah lama berlangsung antara kampung ST dan kampung $\mathrm{AB}$ dalam masa pemerintahannya selama 27 tahun (paling lama dalam sejarah desa $\mathrm{S}$ dengan melalui pengangkatan 2 kali. Suatu cacat pada dirinya sebagai seorang kuwu, ialah hubungannya dengan banyak wanita. Juga banyak gossip tentang penyelewengan-penyelewengan yang dilakukan pamong desa termasuk dirinya, namun gosip-gosip semacam itu tertutup oleh tindakan-tindakan baik yang lain, sehingga hal-hal tersebut tidak menghalangi kecintaan rakyat terhadap kuwunya, dan selama pemerintahan kuwu tersebut menurut banyak responden dikenal sebagai jaman keemasan Desa S.

Dari kasus di atas ternyata bila dihubungkan dengan pemikiran Etzioni, untuk masyarakat desa di Jawa perlu ditambahkan unsur nepotisme sebagai salah satu jenis kekuasaan yang diterapkan dan unsur kesetiaan (setia/cinta) sebagai salah satu jenis keterlibatan peserta yang membentuk tipe kongkruen. Untuk memperjelas, dapat dilihat pada Tabel 2.

Dengan demikian pemikiran Etzioni yang berlandaskan pada masyarakat modern telah terkoreksi berdasarkan kenyataan yang ada pada masyarakat di Jawa.

\section{KESIMPULAN}

Berdasarkan kerangka Tjondronegoro dan Etzioni yang diterapkan pada struktur masyarakat dan kepemimpinan di Jawa maka dapat disimpulkan bahwa:

1. Nepotisme mengendor hanya di beberapa tempat/desa di Jawa tetapi di desa lain di Jawa masih tetap dipertahankan.

2. Adanya gejala bahwa kelompok masyarakat yang paling lemah di pedesaan disingkirkan dari kelompok kerja sama desa.

3. Daya hidup sodality masih dapat ditemukan ditingkat desa

4. Tipe kongkruen untuk pedesaan Jawa adalah tipe Nepotisme-Setia, yang dapat ditemukan pada desa-desa tertentu.

Tabel 2. Tipologi dari hubungan ketaatan

\begin{tabular}{|c|c|c|c|c|}
\hline $\begin{array}{l}\text { Jenis } \\
\text { keterlibatan } \\
\text { Jenis kekuasaan }\end{array}$ & Menarik diri & Pamrih & Moral & Setia \\
\hline $\begin{array}{c}\text { Paksaan } \\
\text { Imbalan }\end{array}$ & Paksaan-Menarik diri & Paksaan - Pamrih & Paksaan-Moral & Paksaan-Setia \\
\hline Normatif & $\begin{array}{c}\text { Normatif-Menarik } \\
\text { diri }\end{array}$ & $\begin{array}{c}\text { Normatif- Pamrih } \\
\text { Imbalan-Menarik diri }\end{array}$ & Normatif-Moral & Normatif- Setia \\
\hline Nepotisme & $\begin{array}{c}\text { Nepotisme-Menarik } \\
\text { diri }\end{array}$ & $\begin{array}{c}\text { Nepotisme- } \\
\text { Pamrih }\end{array}$ & $\begin{array}{c}\text { Nepotisme- } \\
\text { Moral }\end{array}$ & $\begin{array}{c}\text { Nepotisme- } \\
\text { Setia }\end{array}$ \\
\hline
\end{tabular}

Sumber: Pengembangan pemikiran penulis yang didasarkan pemikiran Tjondronegoro dan Etzioni 


\section{DAFTAR PUSTAKA}

Burger, D. H. (1977). Perubahan-perubahan struktur dalam masyarakat Jawa (Vol. 56). Bhratara.

Etzioni, A. (1975). Comparative Analysis of Complex Organizations, Rev. Simon and Schuster.

Isma'il, I. Q. (1997). Kiai penghulu Jawa: peranannya di masa kolonial. Gema Insani.

Lohmann, R. A., \& Lohmann, N. (2002). Social administration. Columbia University Press.

Prijono, Y. M., \& Tjiptoherijanto, P. (1983). Demokrasi di pedesaan Jawa. Penerbit Sinar Harapan.

Sciulli, D., \& Etzioni, A. (Eds.). (1996). Macro socio-economics: from theory to activism. ME Sharpe.
Sutherland, H., \& Sunarto. (1983). Terbentuknya sebuah elite birokrasi. Sinar Harapan. Jakarta.

Tjondronegoro, S. M. (1984). Gejala Organisasi dan Pembangunan Berencana Dalam Masyarakat Pedesaan di Jawa. Dalam Masalah-Masalah Pembangunan. Bunga Rampai Antropologi Terapan. LP3ES. Jakarta.

Turmudi, E. (2004). Perselingkuhan kiai dan kekuasaan. PT LKiS Pelangi Aksara.

Vedung, E.O, (2011). Policy instruments:

Typologies and Theories. In BemelmansVidec, M. L., Rist, R. C., \& Vedung, E. O. (Eds.). (2011). Carrots, sticks, and sermons: Policy instruments and their evaluation (Vol. 1). Transaction Publishers.

Wigna, W. (1979). Nepotisme di Desa: Suatu Studi Kasus di Jawa barat. Prisma, (3). 